\title{
A trajetória do paladar luso entre os séculos XVII-XVIII: análise de livros de cozinha
}

\author{
The trajectory of the Portuguese taste between the 17th-18th centuries: analysis of cookbooks
}

\section{Fernando Santa Clara Viana Junior}

\author{
Universidade Federal do Espirito Santo- UFES - Vitória - Espirito Santo - Brasil
}

\section{Patrícia M. Silva Merlo}

Universidade Federal do Espirito Santo- UFES - Vitória - Espirito Santo - Brasil

\begin{abstract}
Resumo: Buscamos neste trabalho compreender a transição da alimentação portuguesa ocorrida no período entre os séculos XVII-XVIII, influenciada pelas tendências francesas, consideradas modelo para grande parte da Europa moderna. Além das alterações de práticas e técnicas culinárias, buscamos observar a modificação dos ingredientes, estes que constituíram o principal foco das inovações. Falar da modernidade é remeter a um período em que os sabores marcantes das especiarias, usadas em abundância, e a pompa excessiva nas apresentações dos pratos, tão características do medievo, deram lugar a sabores mais delicados, com temperos que valorizavam o sabor natural dos alimentos. Com vistas a acompanhar tal processo, tomamos como base de análise de reflexão os dois primeiros livros de cozinha portugueses publicados: Arte de Cozinha (1680), de Domingos Rodrigues, e Cozinheiro Moderno ou Nova Arte de Cozinha (1780), de Lucas Rigaud. Por esse expediente, buscamos esquadrinhar, em linhas gerais, quais foram as transformações ocorridas no paladar português ao longo do período em tela.
\end{abstract}

Palavras-chave: Processo civilizador. Cozinha moderna portuguesa. Livros de cozinha

\begin{abstract}
We seek in this work to understand the transition from Portuguese alimentation occurred in the period between XVII-XVIII centuries, influenced by French trends, considered a model for a large part of modern Europe. In addition to the changes of culinary practices and techniques, we observe the modification of ingredients, which constituted the main focus of innovations. Talking about modernity is refer to a period in which the striking flavors of spices, used in abundance, and the excessive pomp in the presentations of the dishes, so characteristic of the medieval period, gave way to more delicate flavors with seasonings that valued the natural flavor of food. To follow such a procedure, we take as the basis of reflection analysis the first two Portuguese cuisine books published: Arte de Cozinha (1680), from Domingos Rodrigues, and Cozinheiro Moderno ou Nova Arte de Cozinha (1780), from Lucas Rigaud. For this work, we seek to scan, in general terms, what are the changes in taste Portuguese over the period.
\end{abstract}

Keywords: Civilizing Process. Modern Portuguese cuisine. Cook books. 


\section{A emergência da Alimentação como objeto da} História

A alimentação figura atualmente como um objeto importante para as discussões levantadas pela história. Vale ressaltar que esse movimento emergiu junto com renovação iniciada na década de 1970, colocando em evidência uma gama variada de temas - tais como alimentação, vestuário, imaginário etc., o que impulsionou as produções na área da história cultural e renovou as discussões por meio de um leque cada vez mais amplo de possibilidades (BURKE, 1992, p. 32-38; REIS, 2003, p. 27-42).

A alimentação, contudo, já fora objeto de reflexões desde a Roma e a Grécia antigas. Naquele período aparecem escritos importantes, como o poema Hedypatheia ("vida de luxo" - 330 a.C.), escrito pelo grego Arquestratus (séc. IV a.C.), e De Re Coquinaria, compêndio culinário com receitas escrito por Apicius (25 a.C. - 37). Mas, na historiografia esse tema tão antigo quanto o próprio homem só logrou espaço a partir de 1970, cujo ponto alto foi a publicação da coletânea História da Alimentação (1998), organizada pelos historiadores Jean-Louis Flandrin (1931-2001) e MassimoMontanari (1949-). A obra apresenta em seu escopo discussões acerca do fazer cotidiano relacionado não somente ao alimento, mas a todos os processos e relações que o cercam, reunindo um grupo significativo de historiadores que escolheram, portanto, a alimentação como objeto de suas pesquisas.

No Brasil, vale ressaltar, o tema já aparece pelo viés da sociologia na década de 1930, quando Gilberto Freyre (1900-1987) trouxe à tona o alimento em sua obra Casa-Grande e Senzala (1933). Abria-se espaço para que outros escritos surgissem, com destaque à rica publicação de Luís da Câmara Cascudo (1898-1986) História da Alimentação no Brasil (1968), perpassando a formação culinária (e) social do Brasil a partir das influências indígenas, africanas e europeias. Tais obras continuam a inspirar os apaixonados pela mesa em um leque cada vez maior de possibilidades interpretativas.

\section{A cozinha de corte e as modificações à francesa}

A alimentação figurou em tratados desde a Antiguidade, mas foi no Renascimento que os compêndios culinários associados aos manuais de comportamento tiveram maior repercussão. O sociólogo Norbert Elias buscou analisar, em sua obra O Processo Civilizador (1939) quais os artifícios que permitiram - ou que conclamaram por - modificações do comportamento substantivas a partir desse período. Em seu estudo, Elias discutiu o próprio conceito de civilização e sua emergência no período moderno, este que se revelou central para a compreensão deste ínterim e das inovações que o caracterizaram (ELIAS, 2011, p. 65-80).

De fato, grande foi a produção de manuais que tinham por objetivo ensinar novos comportamentos ${ }^{1}$ a uma nobreza que, oriunda de uma cavalaria guerreira medieval, via o rei tornar-se detentor de um poder cada vez maior (ELIAS, 1993, p. 16-18). As guerras cederam paulatinamente espaço às disputas entre os nobres cortesãos, deslocando o campo de batalha para o interior da corte (ELIAS, 2011, p. 72-80). Assim, ao longo da Modernidade modificam-se uma série de estruturas sociais; alteram-se, conforme destacou o historiador Jacques Revel, as linguagens dos corpos (2009, p. 168-169).

Assim, ficou a cargo da corte - especialmente a corte francesa, esta que muito cedo já se conformara enquanto estamento social e dotada de um papel sui generis (cf. ELIAS, 2011, p. 79; LOPES, 2012, p. 72) - a produção de um corpus de protocolos e etiquetas, que reforçavam demandas sociais daquele momento, quais sejam o autocontrole e o refinamento dos atos. Desta forma, tal corte tornou-se referência de civilidade, pois, além de tratar-se da nação mais rica da modernidade (ELIAS, 1993, p. 29-

\footnotetext{
${ }^{1}$ Para conhecer um pouco mais sobre esses manuais de comportamento, sugerimos a leitura de CASTIGLIONE, Baldassare. O Cortesão. (1 ${ }^{a}$ edição 1528) - São Paulo: Martins Fontes, 1997 e Roterdã, Erasmo. De Pueris.(1 ${ }^{\text {a }}$ edição 1530) 2. ed. - São Paulo: Escala, 2008.CASTIGLIONE, Baldassare. O Cortesão. (1 a edição 1528) - São Paulo: Martins Fontes, 1997 e Roterdã, Erasmo. De Pueris. (1ª edição 1530) 2. ed. - São Paulo: Escala, 2008.
} 
33; 72-73), converteu-se em exportadora de maneiras e linguagens tidas como refinadas, o que permitia a sua distinção em relação às camadas apresentadas como inferiores da sociedade (ELIAS, 1993, p. 17).

A modernidade é, portanto, o período em que tal processo civilizador entra em movimento. De maneira geral, a civilização pode ser entendida, segundo Norbert Elias, como

uma grande variedade de fatos: ao nível de tecnologia, ao tipo de maneiras, ao desenvolvimento dos conhecimentos científicos, às ideias religiosas e aos costumes. Pode se ao tipo de habitações ou à maneira como homens e mulheres vivem juntos, à forma de punição determinada pelo sistema judiciário ou ao modo como são preparados os alimentos. [...] Não há nada que não possa ser feito de forma "civilizada" ou "incivilizada". [...] Este conceito expressa a consciência que o ocidente tem de si mesmo. [...] Com essa palavra, a sociedade ocidental procura descrever o que lhe constitui o caráter especial e aquilo de que se orgulha: o nível de sua tecnologia, a natureza de suas maneiras, o desenvolvimento de sua cultura científica ou a visão de mundo (2011, p. 23).

Assim, a égide de novos hábitos e maneiras que culminaram com o advento do Estado Moderno, revela-se, inclusive, em modificações aferíveis a partir da cozinha e da alimentação. A modernidade inaugura uma série de transformações, não somente nas relações entre indivíduos, como também em suas relações com o mundo. A alimentação, portanto, não foge à regra.

Se até o século $\mathrm{XVI}$, o alimento sempre esteve associado à saúde ou à medicina, no decurso da Época Moderna essa relação enfraqueceu, dando lugar a novas preocupações estéticas. As refeições deveriam ser compostas de forma cada vez mais delicada, sendo leves como uma canção, acariciantes como uma ode anacrônica, graciosas como uma pétite poésie, cintilantes como uma gema ou cinzeladas como um camafeu. O homem começava a encontrar, na cozinha e nas artes, novos prazeres (CAMPORESI, 1995, p. 46).

Iniciava-se um processo em que o alimento deveria servir ao paladar (cf. MAZZINI, 1998, p. 254265). E, como visto, sendo a França a grande exportadora de regras de conduta e boas maneiras no período, as modificações ora apresentadas emanam de sua corte e conquistam rapidamente 0 restante da Europa.

\section{Velhos e Novos ingredientes}

Ao longo do medievo, como consequência desse estreito laço da alimentação com a medicina, muitos pratos que traziam em seu escopo características locais, principalmente no que tange ao uso de ingredientes, haviam desaparecido. Buscavam-se no uso incisivo das especiarias, dos ingredientes ácidos e nas cocções de longa duração, principalmente, as soluções para os desequilíbrios alimentares - alimentos que eram tidos como excessivamente úmidos, secos, quentes ou frios (LAURIOUX, 1998, p. 465). Persistiam-se, portanto, o excesso dos temperos, que sobrepujavam os sabores dos próprios alimentos. Já na modernidade, a diversidade de especiarias apresenta uma acentuada queda, restringindo-se à pimenta, ao cravo e à noz moscada, principalmente, para enriquecer os sabores dos alimentos; a canela e o cravo ficaram cada vez mais ligados aos preparos de doces, enquanto o gengibre e o açafrão "só excepcionalmente são usados" (FLANDRIN, 1998, p. 651). O limão, o vinagre e as laranjas azedas, principais acidulantes medievais, perderam cada vez mais espaço ao longo da modernidade, tendo o vinho e o agraço $^{2}$ entrado como coadjuvantes dos ácidos neste período (FLANDRIN, 2009, p. 102-104).

Se as especiarias em excesso foram perdendo lugar, outros ingredientes alcançaram destaque às mesas da nobreza moderna: os legumes, por exemplo, cujo consumo cresce em detrimento das leguminosas, que eram usuais ao longo do medievo (FLANDRIN, 1998, p. 545). Fossem para atuar como temperos aromáticos ${ }^{3}$ ou como acompanhamentos,

\footnotetext{
2 Tipo de suco de uva, feito a partir de uvas verdes ácidas.

${ }^{3}$ Além dos legumes que servem como aromáticos - como é o caso da cebola, da cenoura, do aipo e das chalotas, por exemplo, vale ressaltarmos um aumento considerável do consumo de ervas aromáticas, como o tomilho, a salsa e o coentro (FLANDRIN, 2009, p. 113).
} 
os legumes ganhavam um espaço cada vez de maior destaque. Na Itália renascentista o consumo desses alimentos ocupava lugar importante e, com a ida de Catarina de Médici (1519-1589) à França, levando toda a sua comitiva de cozinheiros para a corte de Henrique II (1519-1959), trouxe com seus gostos e preferências, o hábito de consumo de tais ingredientes (FRANCO, 2001, p. 159-160).

Essa influência pode ser aferida ao compararmos, num período de 100 anos - entre os séculos XVI e XVII - o consumo de alcachofras, cardos e cogumelos ${ }^{4}$, que praticamente dobraram ao longo deste intervalo (FLANDRIN, 1998, p. 544-545). Já os grãos, consumidos largamente ao longo do medievo, perderam lugar às mesas abastadas, sendo associados ao regime alimentar popular. Assim, como parte do jogo de civilidade, portanto, a nobreza abre mão destes ingredientes em sua dieta (FLANDRIN, 1998, p. 646).

As gorduras se configuram enquanto outro elemento importantíssimo no preparo dos alimentos, tanto no medievo quanto na modernidade. Se os sabores acentuados pela acidez e pelo vasto uso de especiarias na Idade Média eram comuns, a estes devemos acrescentar o uso da gordura de porco nas preparações. Esse ingrediente era descrito nos receituários como toucinho ou manteiga de porco. De fato, era a gordura predominante nos preparos das refeições, de embutidos e charcutaria e no preparo de massas de tortas. Na modernidade, contudo, seu uso decresceu, dando espaço de destaque às gorduras de origem bovina: a manteiga e o creme de leite (FLANDRIN, 1998, p. 652-653). Na França, tais gorduras, por serem consideradas mais delicadas, faziam jus às refeições mais leves, cada vez mais apreciadas graças aos novos padrões. Também o azeite, de grande utilidade ao longo da Idade Antiga, mas pouco utilizado durante a Idade Média, recupera seu lugar de destaque, sem se sobrepor à manteiga e ao creme de leite que ocupavam a preferência dos paladares.

\footnotetext{
${ }^{4}$ Até o século XIX, os cogumelos eram considerados legumes (FLANDRIN, 1998, p. 545).
}

No que se refere às carnes, destacamos o consumo acentuado de aves ao longo do medievo especialmente as aves maiores - em detrimento das carnes de açougue, consideradas pesadas e ideais aos "estômagos grosseiros", não aos da elite (FLANDRIN, 1998, p. 643). Na modernidade, porém, essa tendência ganhou outras nuances: a quantidade de espécies de aves consumidas caiu vertiginosamente, nomeadamente o consumo de carnes de caça. Por outro lado, uma nova espécie entrou em evidência: o peru, oriundo das Américas, rapidamente ganhou os paladares europeus. As carnes de açougue, por sua vez, se faziam cada vez mais presente às mesas abastadas, a ponto de surgirem cortes especialmente voltados para determinados tipos de preparações (FLANDRIN, 1998, p. 643-648).

Também o açúcar granjeou realce ao longo da modernidade. Até o século XVI, vale lembrar que era tido como uma especiaria, sendo utilizado frequentemente como um tempero. Somente a partir do século XVII que o produto deixou, lentamente, de ocupar o posto de especiaria, conferindo sabor adocicado ou agridoce à comida, para ocupar um lugar independente, o das sobremesas, que se tornaram cada vez mais indispensáveis às refeições. À medida que oferta de açúcar aumentou na modernidade (LEMPS, 1998, p. 612), ingredientes como o mel tiveram seu uso diminuído, dando lugar ao surgimento da confeitaria, um espaço específico para a produção de sobremesas e trabalhos com 0 açúcar (CASCUDO, 2011, p. 299-319).

No campo das técnicas de cocção a modernidade também trouxe novidades. A cozinha medieval tinha nos métodos que utilizavam o calor úmido, ou seja, água e/ou caldos, executados ao longo de um grande período, seu principal arsenal técnico (FLANDRIN, 1998, p. 649). Já a Idade Moderna apoia-se em técnicas de cocção rápidas, por meio de calor seco, com o uso de gorduras. Esse processo de transição começa a comportar, por exemplo, os guisados, pratos que são feitos por meio de cocção mista - ora calor seco, ora calor úmido presentes no período moderno. Cabe lembrar que as 
gorduras, por atingirem temperaturas muito superiores, cozinham o alimento mais rápido que os caldos, que não passam dos 100ํㅡ. Dessa forma, a refeições começam a ficar mais coloridas, mais rápidas e com sabores e aromas cada vez mais peculiares (FLANDRIN, 2009, p. 109-112).

Essa cozinha moderna que estava em ascensão não pode ser dissociada de um personagem fundamental: o cozinheiro. Se ao longo do medievo ele era mais um serviçal destinado somente à produção alimentícia, a modernidade reservou a ele um papel diferente e importante. Em meados do século XVII, quando François Pierre (1615-1678) - também conhecido como La Varrene publicou seu livro de cozinha Le Cuisinier Fraçoise (1651), já se observa um papel ativo do cozinheiro frente à escolha dos alimentos e à sugestão de menus na composição das refeições. Quiçá fosse esse um indício do processo moderno de autonomia da cozinha em relação à medicina. Desta forma, o cozinheiro deixava, em parte, de estar apenas à mercê das decisões da rotina alimentar vindas da aristocracia, dialogando com seus empregadores, ocupando um papel ativo na composição das refeições, ou, nas palavras de Jacques Revel (1996, p. 221), tornando-se um "cozinheiro pensante".

Essas alterações na cozinha - assim como em outras esferas da vida aristocrática -, em seus ingredientes e nos papéis assumidos pelos protagonistas dessa atmosfera gastronômica, não se restringiram, como dito, à França. Espalharam-se por toda a Europa cortesã, reforçando a figura real como o centro de administração territorial. Com Portugal, nosso objeto de análise, não foi diferente. Apesar das peculiaridades do Reino, o modelo francês tornou-se fonte de inspiração nesse processo de modernização. É o que buscamos aferir a seguir, tomando por base a análise dos primeiros livros de cozinha portugueses do período.

\section{Portugal, Arte de Cozinha e a cozinha cortesã (século XVII)}

A história ibérica é abalizada por uma série de conflitos no transcurso da modernidade. Entre 1580 e 1640, Portugal esteve sob a regência dos Habsburgos, submetido ao governo espanhol e a um rei ausente (ÁLVARES, 2000, p. 114). O período seguinte foi marcado pela tentativa lusa de legitimar sua nova monarquia, assim como os rituais que cercavam a recém reestabelecida Corte (cf. TORGAL, 1984, p. 308; VALLADARES, 2000, p. 39).

Vale ressaltar que apesar da reconquista da independência política, até o final da década de 1660, os cerimoniais de Corte ainda estavam sob uma forte influência espiritual e religiosa, sendo estes os pendores que guiavam as questões estéticas, literárias e artísticas (LOURENÇO, 2003, p. 53-54). Segundo a pesquisadora Maria Paula Lourenço, não podemos falar de um cerimonial autenticamente luso neste momento, haja vista as condições nas quais se encontravam Portugal. O cerimonial que compunha o Reino era, na verdade, um conjunto formado sob uma gama de influências externas, especialmente o modelo cerimonial habsburgo/castelhano-borgonhês ${ }^{5}$. Essa fora a realidade vivida pelo reino até o período regencial de d. Pedro II (1648-1706).

Foi durante este período que o regente preferiu, no que tange ao cerimonial cortesão, inaugurar um período de certo recolhimento (XAVIER, 1998, p. 48). Apesar disso, foi durante o reinado de $d$. Pedro II que Portugal passou a contar com os mais importantes elementos das cozinhas reais europeias, como o hábito de comer em público, definitivamente instaurado no período (PEREIRA, 2012, p. 21). Contudo, os elementos fundamentais da moda francesa foram adaptados aos gostos e exigências nacionais, a ponto do luxo ser combatido por meio das leis pragmáticas instauradas (cf. ROSSINI, 2010).

\footnotetext{
${ }^{5}$ Este cerimonial tratou-se de um sincretismo de tendências modistas de comportamento cortesão, importadas pelos portugueses da Espanha. Não se trata, porém, de uma mera importação, haja vista o momento vivido naquele momento: a União lbérica. Assim, o cerimonial de referência em toda a Ibéria é o Espanhol, com ênfase ao da família Habsburgo.
} 
O primeiro manual impresso de cozinha portuguesa, Arte de Cozinha (1680), escrito pelo cozinheiro - pensante - português Domingos Rodrigues (1637-1719) veio a público durante o reinado de D. Pedro II. O mestre de cozinha esteve a serviço de sua majestade e da rainha d. Francisca Isabel de Saboia ${ }^{6}$ (1646-1683) (RODRIGUES, 2008, p. 54).

Sendo natural de Vila Cova, Rodrigues dedicou boa parte de sua vida à corte. Pouco se sabe sobre sua trajetória pessoal, além do que consta no prólogo, em suas palavras:

Com o exercício de 29 anos e assistência dos maiores banquetes desta Corte, e de todos o da Casa Real, me habilitei para fazer esta Arte. Todas as coisas que nela ensino, experimentei por minha mão, e as mais delas inventei por minha habilidade. Creio provavelmente que a todos será útil; e quando não o seja a todos, ao menos quisera que todos me agradecessem, não o trabalho que tive, mas o grande desejo que tenho, de que o seja; porque razão é, que me agradeça a boa vontade, com que solicito agradar a todos, ensinando-lhes 0 que sei (RODRIGUES, 2008, p. 54).

Ao todo, a primeira edição de sua obra compreende 270 receitas divididas em duas partes: a primeira, "Modo de cozinhar vários manjares e diversas iguarias de todo gênero de carnes, tortas, empadas, pastéis etc.", soma 163 receitas; a segunda, "Modos de cozinhar vários guisados de peixe, mariscos, ervas, frutas, ocos, laticínios, conserva e toda a sorte de doces", engloba 107 receitas.

A segunda edição da obra, datada de 1683, apresenta uma longa dedicatória ao Conde do Vimioso, o mecenas que assegura o patrocínio à confecção da obra. É nessa edição que Rodrigues explica suas motivações para a escrita do livro:

Não devem os homens só saber para si, porque isso é enterrar o talento que Deus Ihe deu, devem sim comunicar os

\footnotetext{
${ }^{6}$ A rainha d. Francisca Isabel de Saboia já tivera como consorte, a essa altura, o rei d. Afonso IV (com quem teve o casamento anulado, acusando o marido não o ter consumado) e d. Pedro II. A ela foi atribuído o papel de responsável pelo refinamento do gosto português. Era prima de Luís XIV, a quem buscou atender os interesses e já havia tido contato com as novidades preparadas por La Varrene (cf. BRAGA, 2012).
}

empregos de sua habilidade, para que os menos inteligentes, ou aprendam o que não sabem, ou saibam o que não aprenderão. [...] Confesso que me animei a não reparar na minha insuficiência, ainda que me arguam, de que havendo tão grandes ofícios eu faça Arte de Cozinha; porque eu não escrevo para os que sabem, nem para os que sabem murmurar, mas faço Arte para os que não sabem e para os que só sabem aprender (RODRIGUES, 2008, p. 53).

A terceira edição data de 1698, sendo a última publicada com o autor ainda vivo. Nela foi inserida uma terceira parte, destinada à "forma como se hão de dar os banquetes em todos os meses do ano" (RODRIGUES, 2008, p. 171), de modo a dispor formulações de menus para serviços em várias ocasiões. Nela é possível encontrar, além das sugestões de refeição para todos os meses do ano, a organização dos pratos sobre as mesas (ora chamadas de cobertas), uma forte característica da cozinha moderna (ROMAGNOLI, 1998). No início do século XIX, porém, pelo menos a partir da edição de 1814, a Arte de Cozinha passou a integrar uma quarta parte que tratava de "Fazer Pudins e preparar Massas".

\section{Arte de Cozinha e a modernização da cozinha lusa}

Refletindo sobre o processo de modernização da cozinha europeia apresentado anteriormente, buscaremos agora verificar em que medida o livro português, A Arte de Cozinha abarca ou não tais inovações. Procuramos por esse expediente aferir de que modo a cozinha da corte lusa dialoga com esse afrancesamento.

Iniciamos analisando o uso dos ingredientes que compõem a obra - em nosso caso, até a terceira edição. Como visto, o uso de especiarias teve seu uso cada vez mais suavizado na passagem do medievo à modernidade. Na obra lusa, é possível notar, contudo, uma forte influência medieval: $76 \%$ das receitas utilizam especiarias em seus preparos. $\mathrm{O}$ número de especiarias, porém, diminuiu, o que se apresenta como característica de uma cozinha 
moderna: usava-se a pimenta, o cravo da índia e noz moscada.

Os ingredientes ácidos, normalmente aliados às especiarias, faziam coro aos fortes sabores do medievo. O vinho, a laranja azeda e o limão eram característicos deste período; na modernidade, tais ingredientes foram substituídos, em parte, pelo vinho branco e pelo agraço. Assim, numa mescla entre ingredientes ácidos característicos do medievo e da modernidade, 205 produções listadas na obra de Rodrigues evocam a associação entre ácidos e especiarias. O que revelaria um processo de transição entre as formulações culinárias características do momento.

Já os legumes adquiriram especial importância ao longo da modernidade. No receituário português podemos perceber o uso significativo de alcachofras, alcaparras, alho-porró, aspargos, berinjela, cardos e ervilhas frescas. Tal é a importância desses ingredientes na obra de Rodrigues, que há uma seção especialmente dedicada a eles, "De ervas" (RODRIGUES, 2008, p. 139-141), contendo 12 receitas. Por outro lado, o uso de ervas aromáticas teve uma evolução mais tímida que os legumes na modernidade. No livro do mestre Domingues, $5 \%$ das receitas evocam o uso de cebolinha, coentro, hortelã, manjerona, orégano, salsa, louro, sálvia, tomilho etc. Também seguindo a tendência geral de queda no consumo de cereais ao longo da modernidade, na obra de Domingos apenas 5\% das receitas utilizam algum cereal, sendo o arroz o mais aludido.

Outra característica da modernidade, como vimos, foi o consumo de elementos frescos. As frutas frescas, portanto, ganham especial destaque neste momento da história; na verdade, em Portugal podiase observar um aumento no consumo de frutas nas refeições desde o século XV (BORGES, 2011, p. 7375). Estes ingredientes, portanto, foram amplamente utilizados na obra de Rodrigues, associadas a preparações salgadas e doces, correspondendo a $15 \%$ das receitas. No que tange à utilização do açúcar, por sua vez, o ingrediente aparece em 38\% das receitas da obra, ocupando ora o lugar de especiaria, ora o ingrediente de destaque, como associado a frutas na produção de doces.

No que diz respeito à utilização da gordura suína no preparo dos pratos, apesar da tendência geral para a substituição desse tipo de gordura pela a manteiga, principalmente, Arte de Cozinha apresenta um número ainda significativo de preparos à base de grasso suíno: $46 \%$ das receitas utilizavam o toucinho ou a manteiga suína. A manteiga, gordura retirada do leite de vaca, porém, produto recém-chegado da França, já tinha seu espaço na cozinha portuguesa, correspondendo a 33\% das preparações.

O azeite, utilizado largamente ao longo da antiguidade e em menor escala no período medieval, também recuperou seu lugar de destaque. Em Portugal, especialmente, 0 azeite era muito apreciado, sendo que $60 \%$ das receitas da obra incluem seu emprego.

Como apontado anteriormente, a redução na espécie de aves servidas é uma característica da modernização da cozinha, assim como o uso do peru. De fato, das 270 receitas analisadas, $28 \%$ delas utilizam aves num reduzido número de espécies, o que localiza Arte em seu contexto. Também as carnes de açougue ganhavam destaque na Europa moderna e em Portugal, presentes em 30\% das receitas do livro. A carne suína, por sua vez, assim como sua gordura, ainda era muito apreciada em Portugal e fora citada em $38 \%$ das receitas da obra de Rodrigues, o que demonstra a predileção dos paladares por sabores tradicionais.

Talvez o aspecto menos moderno de Arte de Cozinha esteja relacionado às técnicas de cocção. $A$ maioria das receitas da obra utilizam o calor úmido, correspondendo a $90 \%$ das receitas, ao passo que somente $10 \%$ delas empregam somente a gordura em seu preparo. Nesse sentido, os preparos mantinham-se mais medievais que modernos.

\section{Portugal, Nova Arte de Cozinha e a nova cozinha cortesã (século XVIII)}

Ao contrário de todas as complicações que atravessaram o início do século anterior, os 
setecentos começaram com um período de relativa estabilidade; relativa, pois a Guerra da Sucessão de Espanha (1702-1714) ocorria ali ao lado. Já em 1706, quando D. João V (1689-1750) assumiu o trono, as mudanças à francesa da corte portuguesa tornavamse evidentes. Sobre tal momento, o pesquisador Antônio Filipe Pimentel (2008, p. 134) nos diz que

[...] em rota de aproximação cultural e política com o universo das suas congéneres europeias, entre as quais se procura afirmar, não poderia, naturalmente, distanciar-se do modelo geral e a grande novidade - em constante construção, porém, desde os tempos de D. Pedro II [...] - reside, justamente, na crescente abertura a um horizonte de ambições putativamente universal.

A emergência, portanto, de uma ordem cada vez mais internacionalizada se instaurou desde o governo de d. Pedro II, mas foi no período de d. João $\mathrm{V}$ que isso, certamente, ganhou nuances mais claras. A descoberta do ouro no Brasil, que marcou este período regencial, foi crucial para o sustento dos cerimoniais de corte durante o período joanino, o que conferiu à mesa e às outras instâncias cortesãs uma "visibilidade sem procedentes próximos" (MONTEIRO, 2000, p. 136). Isso possibilitou investimentos maciços no estabelecimento das condutas cortesãs e da supremacia régia, sendo $\mathrm{d}$. João V conhecido como o Rei Sol Português, já que fizera por Portugal o que Luís XIV teria feito pela França (MONTEIRO, 2000, p. 137).

A segunda metade do século XVIII, sob 0 reinado de d. José I (1714-1777), Portugal passou por uma intensa transformação mental e social, impulsionada por forças externas e internas, especialmente a efervescência ideológica promovida pela ideia da força da razão. Por outro lado, o Grande Terremoto de 1755 acelerou ainda mais as reformas lusas (MERLO, 2014, p. 2585). Face ao cenário de destruição e a urgência de reconstruir Lisboa e arredores, D. José I teve poucas oportunidades para investir nas questões cortesãs.

Com sua morte, D. Maria I (1734-1816) assumiu o trono. Seu governo deu continuidade ao processo de modernização da sociedade lusa, apesar de sua forte índole religiosa. Nesse período ocorreu a criação da primeira biblioteca pública do país, a fundação da Escola de Belas Artes e da Academia de Ciência de Lisboa (BOLÉO, 2009, p. 25). Além disso, fora em seu governo que o segundo livro de cozinha português foi escrito. Publicado em 1780, Cozinheiro Moderno ou Nova Arte de Cozinha foi escrito pelo cozinheiro francês Lucas Rigaud a convite de d. Maria I.

De origem francesa, Rigaud já havia passado por diversas cortes europeias, como casas em importantes casas de Paris, Londres, Turim, Nápoles e Madri. Trazia grande influência de Vincent La Chapelle, importante cozinheiro francês que atuou por algum tempo na corte de D. João V (BRAGA, s/d). Rigaud escrevera seu livro para, em suas palavras, corrigir o livro anterior, que era "defeituoso, que sem Ihe notar os erros, e impropriedades em particular, se deve registrar inteiramente como inútil, e incompatível com os ajustados ditames da mesma arte" (RIGAUD, 1780, p. 3). A obra reuniu 792 receitas.

Interessa-nos agora aferir em que medida avançou o processo de modernização iniciado com a publicação de 1680, apontando semelhanças e distinções.

No que tange ao uso de especiarias, estas aparecem em $72 \%$ das receitas da obra. Apesar do significativo uso de tais ingredientes, sua variedade continua extremamente diminuta, mantendo o padrão já iniciado em 1680.

Os ingredientes ácidos perdem ainda mais espaço, apresentando-se como um indicador do processo de modernização da cozinha portuguesa. Visto de forma extremamente diminuta, em apenas 34\% das receitas, os ácidos perdiam efetivamente seu espaço frente à sua utilização no livro anterior. $O$ agraço já aparecia muito pouco, tendo o limão ganhado mais destaque na obra de Rigaud.

Os legumes figuraram em $33 \%$ das receitas, tendo as chalotas, legume híbrido da cebola com o alho, granjeado notório destaque. No que tange ao uso de ervas aromáticas, estas aparecem em 50\% das receitas da obra, intensificando o processo iniciado com Domingos. Também o uso de grãos 
continua em queda vertiginosa, aparecendo somente em 5\% das preparações propostas na obra de 1780.

O uso da gordura suína tem uma queda perceptível na obra de Rigaud, quando comparada à de Domingos Rodrigues. A obra de 1780 inclui esse ingrediente em $37 \%$ de suas receitas. Enquanto a manteiga, ingrediente característico da moderna cozinha francesa, aparecia em $50 \%$ das receitas. 0 azeite, ainda a principal fonte de gordura vegetal à época, aparece em menos de $10 \%$ das receitas.

As carnes na obra de Rigaud ganham notório destaque. Além de abrirem a obra do Francês, respondem por parte significativa do Cozinheiro Moderno, 34\% do total de receitas. Dessas, mais da metade eram carne de açougue, um quarto de carne suína, e o restante, carne de aves. Como é possível notar, houve uma queda no consumo da carne suína, além de uma diminuição na variedade de aves; e, por outro lado, o consumo da carne de peru (4\% das receitas) ganha os paladares europeus, todas essas tendências da modernidade, como visto.

No que se refere ao uso do açúcar, vale destacar, naquele momento seu uso já havia consolidado um lugar de destaque à mesa, compondo as sobremesas e deixando os preparos salgados. Nota-se que, dos $18 \%$ dos preparos que usam tal ingrediente, metade destina-se aos pratos exclusivamente doces, o que permite aferir uma mudança no paladar e na maneira como se comia.

As técnicas de cocção dividem-se de maneira quase simétrica. $\mathrm{O}$ uso do calor úmido e longo corresponde a 53\% das preparações, bem abaixo do uso desta técnica na obra de Rodrigues. Por sua vez, o uso do calor seco no Cozinheiro Moderno, 47\%, representa um número quase cinco vezes maior que o da obra anterior. Esse é sem dúvida um importante marcador no processo de modernização da cozinha.

\section{Considerações finais}

Ressaltamos, assim, que a vida cortesã e os cerimoniais de corte adquiriram opulência e identidades características no transcurso da modernidade. A cozinha moderna, como partícipe desse processo, adquiriu nuances próprias, como procuramos apresentar. A França foi o polo principal de onde emanaram as novas demandas, alterando desde o status do cozinheiro, ao uso de ingredientes e culminando com mudanças nas técnicas de cocção e no paladar comum aristocrático. Procuramos apresentar indícios de que Portugal participou ativamente desse processo ao longo da modernidade, seja por meio da produção de livros de cozinha, seja pelas modificações defendidas nesses tratados.

\section{Referências}

ÁLVARES, Fernando Bouza. Portugal no Temo dos Filipes: política, cultura e representações (15801668). Lisboa: Edições Cosmos, 2000.

BOLÉO, Luísa Viana de Paiva. D. Maria I: a rainha louca. Lisboa: A Esfera dos Livros, 2009.

BORGES, Inês da Conceição do Carmo. "A fruta na gastronomia quatrocentista/quinhentista e seiscentista portuguesa". In: Revista Estudios Avanzados, n. 16, dez. 2011, pp. 71-102

BRAGA, Isabel Drumond. "Dona Maria Francisca Isabel de Sabóia (1646-1683), Rainha de Portugal". In: RAVIOLA, M. A. L. B. A. (coord.). Portugal e o Piemonte: a Casa Real portuguesa e os Sabóias. Coimbra: Imprensa da Universidade de Coimbra, 2012, pp. 167-210.

Influências Estrangeiras nos Livros de Cozinha Portugueses (séculos XVI-XIX): alguns problemas de análise. Disponível em <http://ler.letras.up.pt/uploads/ficheiros/4857.pdf>, p. 237-247. Acesso em 9 dez 2014.

BURKE, Peter. A Revolução Francesa da Historiografia: a escola dos Annales (1929-1989). 2. Ed. - São Paulo: UNESP, 1992.

CAMPORESI, Piero. Hedonismo e Exotismo: a arte de viver na época das Luzes. - São Paulo: UNESP, 1995.

CASCUDO, Luís da Câmara. História da Alimentação no Brasil. 4. Ed. - São Paulo: Global, 2011.

ELIAS, Norbert. O Processo Civilizador, vol. 1. 2. ed. - Rio de Janeiro: Zahar, 2011.

O Processo Civilizador, vol. 2. - Rio de Janeiro: Zahar, 1993.

FLANDRIN, J. L. "A Moderna Cozinha Europeia: uma encruzilhada de experiências culturais (séculos XVIXVIII)". In: MONTANARI, Massimo (org.). O Mundo na Cozinha: história, identidade, troca. - São Paulo: Estação Liberdade; Senac, 2009, pp. 98-119. 
FLANDRIN, J. L.; MONTANARI, M. História da Alimentação. - São Paulo: Ed. Estação Liberdade, 1998.

FRANCO, Ariovaldo. De Caçador a Gourmet: uma história da gastronomia. 5a . Ed. - São Paulo: Editora Senac São Paulo, 2001.

LAURIOUX, Bruno. "Cozinhas Medievais (séculos XIV-XV)". In: FLANDRIN, et. al., 1998, op. cit., pp. $447-465$

LEMPS, Alain H. "As Bebidas Coloniais e a Rápida Expansão do Açúcar". In: Flandrin, et. al., 1998, op. cit., pp. 611-624.

LOPES, Marco Antonio. O Imaginário da Realeza: cultura política ao tempo do absolutismo. - Londrina: Eduel, 2012.

LOURENÇO, Maria Paula Marçal. "Os Séquitos das Rainha de Portugal e a influência dos estrangeiros na construção da 'sociedade de corte' (1640-1754)". In: Penelope - Revista de História e Ciências Sociais, n. 29, pp. 49-82.

MAZZINI, Inocenzzo. "A Alimentação e a Medicina no Mundo Antigo". In: FLANDRIN, et. al., 1998, op. cit., pp. 254-265.

MERLO, Patrícia M. S. "Em Razão do Grande Terremoto: observações sobre a política pombalina no reinado de D. José I". Anais - IX Semana de História Política/VI Seminário Nacional de História: Cultura \& Sociedade. - Rio de Janeiro: UERJ, PPGH, 2014, pp. 2582-2589.

MONTEIRO, Nuno G. F. "A consolidação da dinastia de Bragança e o apogeu do Portugal barroco". In: TENGARRINHA, J. (org.). História de Portugal. Bauru: EDUSC; São Paulo: UNESP; Lisboa: Instituto Camões, 2000, pp. 129-148.

PEREIRA, Ana Marques. Mesa Real: dinastia de Bragança. Lisboa: A Esfera dos Livros, 2012.

PIMENTEL, Antônio Filipe. "Os pintores de D. João V e a invenção do Retrato de Corte". In: Revista de História da Arte, n. 5, Lisboa, 2008, pp. 132-151.

REIS, José Carlos. História \& Teoria - historicismo, modernidade, temporalidade e verdade. - Rio de Janeiro: Editora FGV, 2003.

REVEL, Jacques. "Os Usos da Civilidade". In: ARIÉS, Phillipe, et. al. História da Vida Privada, 3: da Renascença ao Século das Luzes. - São Paulo: Companhia das Letras, 2009, pp. 168-210.

RIGAUD, Lucas. Cozinheiro Moderno ou Nova Arte de Cozinha. Lisboa: na oficina do patriarca. de Francisco Luiz Ameno, 1780.

RODRIGUES, Domingos. Arte de Cozinha. Rio de Janeiro: Senac Rio, 2008 [Lisboa: Oficina de João Galrão, 1680].
ROMAGNOLI, Daniela. "Guarda no siivilan: as boas maneiras à mesa”. In: FLANDRIN, 1998, op. cit., pp. 496-508.

ROSSINI, Gabriel Almeida Antunes. "As Pragmáticas Portuguesas de ins do século XVII: política fabril e manufatureira reativa". In: SÆCULUM - REVISTA DE HISTÓRIA, João Pessoa, jan./ jun. 2010, p. 117-135.

TORGAL, Luís Reis. "Acerca do significado sociopolítico da 'Revolução de 1640'”. In: Revista de História das Idéias, v. 6, Coimbra: Universidade de Coimbra, 1984.

XAVIER, Ângela Barreto. "El Rei Aonde Pode \& Não Aonde Quer": razões da política no Portugal seiscentista. Lisboa: Edições Colibri, 1998.

VALLADARES, R. Portugal y la Monarquia Hispánica, 1580-1668. Madrid: Arco/Libros, 2000. 